Stefan Roggenbuck

\title{
Aspectos históricos de la infancia callejera ${ }^{I}$
}

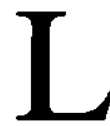

a infancia callejera es considerada como uno de los problemas más gra ves de los países en desarrollo, especialmente en América Latina, donde, según datos estimados, se concentra la mitad de los niños de la callez existentes a nivel mundial.

La investigación sobre la infancia callejera se encuentra lodavía en su fase inicial. Los enfoques presentados hasta ahora son unilaterales y unicausales. Por lo general no tienen en cuenta la complejidad del fenómeno, ya que hay una variedad de motivaciones - lanto psicológicas como sociales-que impulsan a los niños a vivir en la calle y que condicionan sus comportamientos. A parte de eso, no se puede descartar otros aspeclos, como culturales e históricos. El siguiente ensayo trata de indicar aspectos importantes de la historia social de la infancia callejera latinoamericana, la cual todavía tiene que ser escrita. Para comprender la actual problemática de los niños de la calle es imprescindible que se tenga conocimiento de dos tradiciones importantes, que se exponen a continuación.

\section{La tradición del abandono instilucionalizado}

"Un día mi madre quería llamar a la policía para mandarme a una institución. Pero yo no quería, entonces me escapé de mi casa (...) Más tarde le pregunté: Mamá, ¿para qué tienes hijos si no te interesas por ellos? Yo no nací para ir a parar a una institución".

Con estas palabras se expresa el brasileño de trece años de edad, Nuno, representando a muchos niños callejeros de su ciudad (Sao Paulo) y de su país. También en otras urbes latinoamericanas se pueden escuchar estas expresiones, aunque no estén tan claramente formuladas. No es raro que a la huida de los niños callejeros de la casa de su padres anteceda la amenaza de que se les quiere mandar a una institución. Este tipo de comportamiento parece, a primera vista, una "irresponsabilidad" de los padres o padrastros frente a los niños $\longrightarrow$ mejor dicho: una tendencia del comportamiento a evadir la obligación de educarlos. 
Sin embargo, esta inclinación no puede ser interpretada sólo como "irresponsabilidad" de quienes tienen la obligación de brindar la educación. Para brindarles sus causas es necesario dar un vistazo a la tradición del abandono institucionalizado.

Actualmente resulta dificil imaginar que antes, en algunas regiones, la entrega de los niños representaba un procedimiento completamente legítimo y generalmente aceplado. ${ }^{3}$ La entrega de recién nacidos incluso hasla niños mayores estaba institucionalizada en las llamadas "casas de expósitos", en las que se recibía a los niños abandonados o huérlanos. Ya en el año 787, la Iglesia fundó la primera casa de expósitos en Milano, mediante la cual se pretendió contrarrestar la gran cantidad de muertes de niños. Se quería salvar a lodos los niños que, como consecuencia del abandono en ríos o bosques, estaban condenados a morir.

Especialmente en las ciudades italianas, este fenómeno estaba muy difundido. Consecuentemente en Italia se fundaron muchas casas de expósitos. Pero también en Francia hubo preocupación por los expósitos. En 1160, Guy de Montpellier fundó la Orden Hospilalaria del Espíritu Santo, que recogía niños huérfanos. En 1198, el Papa Inocencio III introdujo en Roma el llamado tomo de expósitos. Este era como un medio cilindro que giraba fácilmente sobre el eje vertical, que era instalado frente a una abertura en la pared externa de la casa de expósitos. Desde la calle se colocaban los niños abandonados en este torno. El peso que recibía hacía que el tomo girara hacia adentro y simultáneamente hacía sonar una campana que le anunciaba a la tomera la llegada de un nuevo expósito. Este medio accesible para todos y en cualquier momento, facilitó el abandono de niños en el más completo anonimato y, a la vez, con la certeza de que éstos iban a ser recibidos y atendidos. ${ }^{4}$

Por mucho tiempo y únicamente en Roma existió el tomo de expósitos. Fue mucho después que éste luvo una amplia difusión, la cual se circunscribió a las regiones en las que se había desarrollado una aprobación social del abandono de niños, apoyándose después en la creación de una base jurídica para la legitimación del abandono; todo ésto se dio en el círculo de la cultura romana.5 El sislema de casas de expósitos, difundido aquí principalmente en los siglos XVIII y XIX, hizo de la aceptación incondicional y anónima de los expósitos una regla. La madre soltera tenía el derecho de rehusar desde el principio los cuidados de su hijo. Se consideraba que el hijo ilegítimo no estaba emparentado con sus padres, mientras no fuera reconocido expresamente por éstos. Según el Derecho Civil de entonces, el derecho de abandonar al hijo se extendía en Francia aún hasta los padres legítimos. Estaba prohibido cualquier investigación sobre los padres del niño que había sido abandonado en una casa de expósitos. En algunas regiones de los países que tenían legalizado el abandono, estaba prohibido el intento de descubrir al padre o a la madre de un expósito, incluso bajo la amenaza de un 
castigo corporal. En el abandono, mediante el acto de entrega del niño quedaban rotas todas las relaciones entre madre e hijo, la madre se separaba jurídicamente para siempre de su hijo. 6

Precisamente ésto fue impedido en el sistema de protección infantil del círculo cultural germánico. Aquí se hacía hincapié en las obligaciones de los padres frente a sus hijos, las cuales eran vistas como las más nalurales. La Protección estatal intervenía en forma subsidiaria, protegiendo a la madre y al hijo. Aquí era muy dificil de concebir el procedimiento usual dentro del sistema romano de exposición de niños, mediante el cual se separaba al niño de su madre para siempre. Se ha considerado, que, entre otras, una de las razones de ésto fue que en la cultura germánica desde la Reforma, se cultivó mucho más tiempo el principio de la responsabilidad del individuo por sus propios actos, de acuerdo a lo cual iría en contra de las costumbres el eludir las responsabilidades patemales o maternales. Igualmente eran consideradas contrarias a las costumbres las instituciones que permitían la evasión de estas responsabilidades, tales como las casas de expósitos al estilo romano.?

¿A qué se debía este desarrollo especial de un sistema de casas de expósitos con el reconocimiento estatal y social del abandono? ¿Qué trasfondo teníd el abandono anónimo e institucionalizado de niños? Aquí debe mencionarse un factor decisivo que tiene relación con el honor de la mujer soltera. Con el tomo de expósitos —que es el símbolo del abandono institucionalizado de niños- no sólo se pretendía salvar a los niños abandonados; sobre todo se pretendía borrar la "vergüenza" de la maternidad ilegítima, el "pecado" de la deshonestidad y de facilitar la conversión a la pecadora. Por mucho tiempo y principalmente en los países romanos, bajo la influencia de la iglesia Católica, la matemidad ilegítima fue considerada una vergüenza. 8

Puede tomarse como ejemplo el proceder del filósofo, Jaques Rousseau. Después del nacimiento de sus cinco hijos, concebidos en unión ilegítima, los entregó por medio de una partera a la casa de expósitos de París. En sus confesiones de 1776 menciona las razones por las que lo hizo: "Yo me decidí a hacerlo sin el menor remordimiento. Los únicos remordimientos que tuve que superar fueron los de Teresa (la madre). Me costó mucho trabajo lograr que eligiera el único medio posible para salvar su honor". 9

Todavía a finales del siglo XIX en Roma, una madre soltera que educaba sola a su hijo era considerada "inmoral", y en tales casos también las autoridades eclesiásticas propiciaban la entrega de los hijos. En el sur de Italia se mantuvo esta mentalidad hasta ya avanzado el siglo $\mathrm{XX}$. Se sabe de casos en los que las investigaciones encaminadas a encontrar a la madre de un expósito tuvieron como consecuencia graves perturbaciones sociales, como la muerte del hijo o el repudio y hasta el asesinato de la madre por parte de los parientes para proteger el honor de la familia. 10 
A través de la posibilidad del abandono legal e institucionalizado de niños en las casas de expósitos - las cuales quedaron a cargo del Estado después de la secularización- se multiplicó el abandono de niños. Las casas de expósitos invitaban a entregar a los niños. Precisamente esto fue lo que favoreció la procreación irresponsable de niños, los nacimientos ilegítimos —que de por sí eran numerosos en los países católicos debido a la indisolubilidad del matrimonio, de tal manera que el lazo de la obligación y del amor de padres se fue debilitando entre el pueblo, pues reinaba la conciencia de que era correcto el posterior abandono del hijo y que las autoridades de la Iglesia o del Estado tenían la obligación de cuidar el niño. Aquí podemos utilizar nuevamente las palabras de Rousseau, cuyos principios son representantivos de muchos de sus contemporáneos: "Este medio (la entrega de sus hijos ilegítimos a la casa de expósitos) me pareció tan bueno, tan razonable, tan legítimo, que no me vanaglorié de ello abiertamente sólo por consideración a la madre". Y en una carta explicaba: "Si no existiese un asilo para ellos (sus hijos ilegítimos), asumiría mi obligación y me decidiría mejor a morir de hambre y no a dejar de alimentarlos a ellos".11

Fueron aumentando los abusos que se cometieron con este sistema de abandono legal e institucionalizado de niños. Especialmente en los tomos de expósitos eran entregados y abandonados cada vez más niños legítimos, su porcentaje entre los expósitos llegó a ser de $15 \%$ a $20 \%$. En algunas comunidades de países romanos se puede decir que incluso un tercio de los niños abandonados pertenecían a familias, que ni tan siquiera podían alegar su probreza material como razón del abandono, sino que simplemente preferían que sus hijos fueran educados a costa de otros. No sólo se depositaban recién nacidos en el torno, sino que también niños mayores. En una ocasión, en una casa de expósitos en Francia fue introducido a la fuerza un muchacho sordomudo de 17 años. Las viudas se deshacían de su prole, cuando les hacía estorbo para la próxima unión. Las prostitutas podían depositar en las casas de expósitos a los "productos" no deseados de su "trabajo". Se constituyó como un oficio el llegar a depositar niños en el tomo a cambio de dinero. En Rouen, por ejemplo, hubo una partera que entre 1843 y 1860 llevó 192 niños al tomo de expósitos. De todas partes del país se enviaban niños a los tomos de expósitos de las ciudades para entregarlos a las autoridades. Se desarrolló una "industria de crianza de niños", en la cual muchas nodrizas atendían mal a los expósitos, pues no se preocupaban de amamantarlos y lo que realmente les interesaba era lo que les pagaban las autoridades. De ahí que no fuera de extrañar una alta mortalidad de los huérfanos. Los empleados de las casas de expósilos entregaban los niños a cambio de dinero a mendigos callejeros y éstos los utilizaban para provocar lástima al mendigar. 12

A finales del siglo XVIII y principios del XIX, la cantidad de expósitos en los países que favorecían el abandono legal de niños alcanzó niveles considerables. Su proporción en la cantidad de nacimientos en París por ese tiempo oscilaba entre $20 \%$ y $33 \%$. En el lapso de una década se abandonaron entre 40,000 
y 65,000 niños. Especialmente en la época de Napoleón con la difusión masiva de tornos de expósitos en Francia se promovió el abandono de niños - a la par de las razones que ya se expusieron acerca de la salvación del honor de la madre ilegítima; en ese momento influyeron también las reflexiones militares y de política de población para ia expansión del sistema de casas de expósitos. Cerca del año 1830 se atendía en las instituciones de expósitos alrededor de 130,000 expósitos que eran sostenidos a un costo de diez millones de francos. En Italia, en el año 1866, existieron 1,179 tornos de expósitos. Especialmente allí habían muchos expósitos.13

¿Qué pasó entonces con esta gran cantidad de expósitos legalmente abandonados? Como ya se mencionó con anterioridad, la mortalidad entre los expósitos era muy alta. Al principio no era muy raro que ésła ascendiera a $80 \%$, incluso más allá del $90 \%$. Sin embargo después se pudieron reducir considerablemente estas cifras, al rededor de un 50\%. ¿Qué pasaba con los expósitos que llegaban a adultos? En primer lugar debe decirse que es muy poco lo que se sabe al respeclo. 14 Estaba previsto que fuesen adoptados, principalmente por artesanos que les enseñaron un oficio. A las huérfanas del sexo femenino se les ocupaba en las mismas instituciones de expósitos para cuidar de los niños. Sistemáticamente los mayores fueron estigmatizados como hijos del pecado, como hijos de prostitutas y ladrones, como bastardos, etc. Se les puso una marca externa a través de delerminada ropa, a través de un sello numerado; se les dio el apodo de "huérfano". De esta forma se convirtieron en objeto de burla de la sociedad. Se dice que algunos huérfanos emigraron tratando de escapar de este estigma. 15

¿Qué consecuencias produjo el sistema de las casas de expósitos con el abandono legal y secreto de niños? La intención original humanista con la que se había creado, se había convertido completamente en lo contrario: En primer lugar se estaba fomentando un comportamiento antinatural, al saber que los padres entregaran a sus hijos. En segundo, el descuido en la atención de los huérfanos alcanzó una alta mortalidad de éstos, lo que le dio a las casas de expósitos la reputación de ser cementerios. En tercer lugar, se estaba criando a una clase de discriminados que sólo podían esperar denigración y maltrato por parte de la sociedad. Finalmente, toda esta empresa terminó provocando costos extraordinariamente elevados.

Todo ésto condujo a que por lo menos en la segunda mitad del siglo XIX fuera combatido el sistema de las casas de expósilos. A finales de la década de 1860 dejaron de funcionar en Francia y Portugal los últimos tomos de expósitos. Sin embargo en España y sobre todo en Italia, éslos se mantuvieron aún a principios del siglo XX. Ciertamente se siguí discutiendo por largo tiempo sobre la posibilidad de entregar secretamente a los niños, pero a principios del siglo XX se dio en la Europa romana una ruplura con la tradición arraigada durante siglos 
del abandono inslitucionalizado de niños. Cada vez se veía con más claridad como era el callejón sin salida en que se estaban introduciendo a los niños expósilos.

Se comenź a dar más atención e importancia a las obligaciones de los padres; ya no se acepló la separación de éstos de su hijos sin causas justificadas, precisamente como era usual la asistencia a la niñez en el sistema germano. En este punto volveremos a entrar brevemente, en forma típica-ideal, a la diferencia esencial entre la asistencia de expósitos "romana" y la protección de la niñez "germana". En la primera forma de atención, ésta se da para los expósitos como un grupo especial de niños necesilados. Aquí se separa a los niños del mundo de los adultos y se aislan en su propio mundo. En las casas de expósitos los niños estaban entre ellos mismos. Por el contrario, en la protección "germana" de la niñez no se daba una diferenciación de este tipo de niños como grupo independiente. Dentro de la ayuda general a los pobres, los niños abandonados y los huérfanos eran apoyados por las comunidades junto a los adultos. 16

¿Qué tiene, pues, que ver todo ésto — casas de expósitos, tornos de expósitos, etc., en fin: la tradición del abandono institucionalizado de niños- con el fenómeno de la infancia callejera en Latinoamérica? La tradición proveniente de Europa del abandono institucionalizado de niños encontró rápidamente sus ramificaciones en Latinoamérica. Como demuestran los relatos históricos de niños callejeros en Bogotá, Sao Paulo y Lima, el problema de los expósitos se articuló aquí exactamente igual como en las grandes ciudades de las metrópolis. $17 \mathrm{La}$ fundación de casas de expósitos con tornos no se hizo esperar mucho. Incluso había la jactancia de haberse adelantado en este aspecto a algunos países europeos. 18

Es interesante la relación que se puede apreciar en el caso de Sao Paulo entre niños expósitos y niños callejeros. Primeramente se pueden hacer las conjeturas de Silva 19, de que el problema de los niños expósitos se refería - asi era por lo menos al principio- a la población libre, es decir a los que no eran esclavos, pues según un decreto del año 1775, los niños abandonados de color eran considerados no esclavos. Según Silva, los que tenían esclavos ponían mucho empeño en evitar que sus esclavas abandonaran a sus hijos, pues enlonces habrían perdido fuerzas de trabajo. En el caso de los niños que fueron abandonados en el torno de la casa de expósitos de Río de Janeiro en el siglo XIX, se fortalece la hipótesis de los niños expósitos de raza blanca: Soares expone que muchos sorprendentemente tenían el nombre de algún emperador romano - era usual poner en el tomo junto con el niño, un papel con los datos (fecha de nacimiento, nombre del exposito, etc.). De aquí concluye Soares que las madres de éstos llamados expósitos, de ningún modo podían provenir de condiciones de pobreza, no podían ser esclavas. 20

También se supone que muchos de los niños que se veían vagabundeando y 
mendigando en el centro de Sao Paulo de 1788 a 1825 eran niños expósitos de raza blanca. Esto se dio en el contexto de la suspensión de protección del Juez de Huérfanos con relación a los expósitos de su jurisdicción a partir de los siete años de edad. De todo ésto se puede concluir que los primeros niños callejeros brasileños eran en su mayoria blancos. Otra hipótesis que habría de formularse es que los niños callejeros de los siglos XVIII y XIX habían sido en su mayoría niños expósitos, a los cuales se atendía hasta una determinada edad -en este caso hasta los siete años-, que algún día como consecuencia de la falta de protección pública, se encontraban abandonados a su propia suerte e irremediablemente iban a parar a las calles y allí se convertían en niños callejeros.

También en el caso de Bogotá se pudo establecer la relación entre la falta de funcionamiento de las instituciones públicas de atención y la aparición de niños callejeros; durante la guerra por la independencia y las guerras civiles entre 1810 y 1854 hubo una carencia de atención a la niñez. Precisamente en esta época se presume que surgieron las bandas de niños callejeros. Las casas de expósilos - que aislaban a los niños como un grupo especial del mundo de los adultos- contribuyeron a la constilución de un mundo propio de los niños y, con ello, a una temprana organización de los niños callejeros como grupo independiente, posiblemente una cultura de los niños callejeros, cuya existencia se comprobó en Bogolá y Sao Paulo, a diferencia de Lima. En Lima, la infancia callejera se articuló hasta en el siglo XX. Esta ya existía en forma latente desde el siglo XIX o quizás antes, pero no tomó formas manifiestas tan pronto como en Bogotá y Sao Paulo, debido a la poca cantidad de expósitos que había en comparación con las otras ciudades, y a la continua e íntegra asistencia que se les daba a los expósitos.

De la hipótesis postulada sobre la relación entre los que han sido niños expósitos y los niños callejeros, se puede concluir que el fenómeno de los niños callejeros latinoamericanos en parte tiene origenes europeos. No es de extrañar el hecho que precisamente los países que generaron mayores cantidades de niños callejeros son aquellos en los que se dio una atención masiva de expósitos al estilo "romano", como sucedió principalmente en Francia y en Italia. Especialmente en el sur de Italia, donde existieron los tomos aún ya avanzado el siglo $\mathrm{XX}^{21}$, siguen existiendo los niños callejeros hasta la fecha actual. Todavía a mediados del siglo XX, el Padre Borrelli trabajaba con los niños callejeros de Nápoles ("Scugnizzi").22 En Londres hubo muchos niños callejeros-que se volvieron famosos por la obra "Oliver Twist" de Charles Dickens. Si bien aquí el torno de expósitos y el abandono institucionalizado de niños sólo existió de 1756 a 1760, también aquí se estableció un amplio sistema de casas de expósitos, aunque con otras finalidades en comparación con el país romano, pues aquí de lo que se trataba primordialmente era de multiplicar las fuerzas de trabajo en la época de la industrialización. En cambio el sistema de Rusia (sobre todo en 
Moscú y en San Petersburgo) se parecía más a la asistencia "romana" de los expósitos, pues aquí lo que se perseguía en primer lugar era proteger el "secreto" del nacimiento de hijos ilegítimos. Por eso precisamente no es extraño que haya habido millones de niños callejeros ("Besprizornyj") como una consecuencia de la guerra civil sin poder desconocerse la relación entre la atención de expósitos llevada durante siglos y la inmensa cantidad de niños callejeros —que en esa época fue única en la humanidad.23

Como ya se dijo, la tradición europea del abandono institucionalizado encontró rápidamente sus ramificaciones en Latinoamérica, de donde se derivaron los orígenes del fenómeno de la infancia callejera que se da aquí. En un delerminado momento, cuando en Europa precisamente esta tradición iba disminuyendo cada vez más - a mediados del siglo XIX - ésta se fortaleció en varias partes de Latinoamérica. Esto se debí́ a que en esa época, las vicentinas francesas emigraron en forma masiva a Latinoamérica y promovieron las casas de expósilos. Con ésto se hace alusión a una relación existente entre las órdenes católicas y los niños expósilos y por ende también con los niños callejeros: la asistencia de expósitos (sobre todo la "romana") no puede concebirse sin la influencia de una orden católica, que a través de su accionar contribuyó a la expansión del fenómeno de los niños abandonados en el anonimalo. Previamente se mencionó a la orden del Espíritu Santo que en el siglo XIV tenía 29 casas de expósitos bajo su dirección. En el año 1638 es San Vicente de Paul quien con su fundación establece la primera institución parisina para expósilos, y cuya orden tuvo una gran participación en la atención de sus expósitos en los siglos venideros. 24

La llegada masiva de las vicentinas a Latinoamérica se puede atribuir a que en Europa era cada vez menor la demanda de sus servicios de cuidar los niños abandonados, por las razones que ya se han mencionado anteriormente. Estas fueron bienvenidas en las casas de expósitos latinoamericanas 25 , donde se continuaba todavía con la misma tradición, la cual habría de durar mucho tiempo -en parte también gracias a su influencia-, por lo menos hasta mediados del siglo XX. Alrededor de esta época se empezó también a cerrar las casas de expósitos con el sistema del torno en Latinoamerica.26

Sin embargo con la lucha iniciada para combatir la tradición del abandono institucionalizado de niños no se dio término a la entrega, al abandono de niños. Lo que se había cultivado durante tanlos siglos no puede desaparecer de la noche a la mañana. En Brasil, aún en los años 80 en pleno siglo $\mathrm{XX}$, todavía muchos niños8 son abandonados a falta de tomo, ya sea frente a las iglesias, en los baños públicos, en las estaciones, etc. 27 Otros simplemente son entregados en los albergues infantiles del Estado. Aclualmente no se trata de niños de las clases altas - como eran originalmente los que se ponían en los tornos de las primeras casas de expósilos latinoamericanas - sino que son principalmente los niños de las clases bajas de la población, que cierlamente ya no son abandona- 
dos sin ninguna formalidad, pero siempre son entregados para "adopción", ésto quiere decir que son separados definitivamente de su madre. El Estado paternalisla Iradicional se basa en la "incapacidad" de una parte de la población para educar a sus propios hijos. Esto se pone de manifiesto, por ejemplo, en el código brasileño de menores, en el concepto del "menor en situación irregular"28, así como en las explicaciones de representantes de los órganos oficiales de asistencia a niños y jóvenes, que siempre alegan la "irresponsabilidad" de los padres. $29 \mathrm{Al}$ hacerlo olvidan completamente, que precisamente el esquema se vuelve a reproducir en virtud de la actitud de las autoridades, derivada del abandono institucionalizado, pues toleran la "entrega" de los niños y con ello la "irresponsabilidad" del Estado. Sólo en el contexto de estos factores pueden entenderse las palabras del niño callejero brasileño, Nuno que citamos al principio. De esta manera se puede imaginar el porqué los niños latinoamericanos $-y$ no sólo los niños que posteriormente se vuelven niños callejeros-, están en peligro de ser abandonados, el porqué sus padres carnales los amenazan con "entregarlos".

En vez de fomentar algo natural como es la unión de la madre/los padres con el niño y darle una atención integral al menor, el Estado paternalista sigue cargando con la tarea de hacer frente a la "enlrega" de niños a través de una gran cantidad de instituciones, de ver a los niños como una especie de "propiedad del Estado", de jugar a ser la "madre" de un ejército de niños —en Brasil, a mediados de los años 80, es el caso de 427,0000 o más de ellos. La actuación "irresponsable" del Estado se pone de manifiesto más claramente en aquellos casos en los que las personas se arrepienten de la entrega de su hijo30 y lo reclaman después de años de separación.

La tradición del abandono institucionalizado de niños, continuada de manera no oficial, no podrá desaparecer mientras existan intereses sociales concretos para mantenerla, como puede verse específicamente en el caso del Brasil. En la historia de la ciudad de Sao Paulo se mostró cómo en los años 50, "patrones" inescrupulosos entregaban los hijos de sus empleadas domésticas en los centros de atención del Estado, pues éstos sólo les hacían estorbo a sus madres en el trabajo de la "casa del patrón". Pero aún en los años 80 , en pleno siglo XX, se da todavía ese fenómeno: El 17/06/1984 aparecía una crítica de un juez de menores en el Diario "O Estado de Sao Paulo", si las "señoras de la casa" $\longrightarrow$ sea las esposas de los "patrones" - permitieran que las "empleadas domésticas" conservaran a sus hijos a su lado y dejaran de entregarlos a las instituciones. Este juez de menores exigía una reforma a las leyes y costumbres del Brasil para combatir los "problemas del menor".

¿Cuál es el destino de las actuales víctimas de una tradición "modemizada" de abandono institucionalizado en Latinoamérica? Se puede establecer una cierta similitud con el destino de los expósilos en Europa. Pues en una medida no mucho menor que la de los europeos sin identidad de antaño, los "abandonados" 
latinoamericanos se ven afectados por el estigma y el maltrato de la sociedad. En los centros de atención constituyen un numeroso grupo, una masa, que se supone que en cualquier momento está disponible para satisfacer las "necesidades" de la sociedad. Ya el documento de los años 50 de Nogueira Filho revela como los "abandonados" se volvían cómplices de las escenas criminales. ${ }^{31}$ A la misma época se refieren los datos de Junqueira32, de los que resulta que en un centro público de educación las "damas" de la sociedad de una pequeña ciudad del Brasil, como era la costumbre, iban a traer a las "abandonadas" para que trabajaran sin salarios en sus casas. Igualmente usuales parecían ser las siluaciones sobre las que cuenta Edmundo de una institución de educación pública de Recife. El explica la simple "técnica" utilizada por la dueña de un burdel para que no se le agotara su fuente de prostitutas: Ella reclutaba entre sus nuevas generaciones a las abandonadas de los centros de asistencia que ya eran adolescentes, infiltrando a niñas más jóvenes la cuales se hacían amigas de las internas y que se fugaban con ellas para ir directo al burdel. Aquí les esperaba a las que una vez fueron niñas abandonadas una "nueva" vida en la prostitución. 33

Finalmente, el origen europeo de la tradición del abandono institucionalizado de niños que se ha expuesto en el presente texto y su relación con la infancia callejera debe ser ilustrado con algunas observaciones y conjeturas. Por un lado debe preguntarse, ¿cómo es que precisamente en 1884 los niños callejeros de Bogotá son llamados "gamines" por primera vez? ¿No queda acaso establecido un punto de unión entre los niños callejeros europeos y latinoamericanos con la adopción de este término francés que se ha conservado hasta ahora, quizás no tan inconscientemente? ¿Y no fueron talvez las vicentinas francesas, bajo cuya dirección estaba la casa de expósitos de entonces en Bogotá, quienes empezaron a usar esle término para referirse a los niños callejeros de esta ciudad? Debe considerarse que muchos de ellos habían sido sus pupilos y eran el recuerdo de lo que habían vivido en su patria. En París sobre todo habían en ese tiempo niños callejeros, cuyo estilo característico de vida hizo que de esas expresiones como "gaminería" se introdujeran en los diccionarios.

Por otro lado, a finales del siglo pasado en Sao Paulo se pudo constatar la aparición de "banbini" italianos en las calles que se dedicaban a vender periódicos o lustrar zapatos. Al mismo tiempo, los italianos en Bogotá les enseñaron a los niños callejeros del lugar el oficio de lustrar zapatos. ¿No es acaso llamativo, el que siempre fueran italianos los que introdujeran las ocupaciones clásicas de los niños callejeros -ender periódicos y lustrar zapatos - en ambas ciudades suramericanas? ¿Fue esto simple casualidad? Es decir, ¿acaso no había familiaridad desde hacía tiempo con los niños callejeros? — n ese país en que hubo muchos expósitos, existió el primer tomo y tal vez lambién los primeros niños callejeros.

Finalmente debe observarse que tampoco fue casualidad que los portugueses 
fueran los que expresamente "adoptaran" a los niños vagabundos en Sao Paulo a finales del siglo pasado; o sea que les permitían dormir en sus locales a cambio de algún dinero y al mismo tiempo los utilizaban con fines de explotación. ¿De dónde conocían mejor el trato con los niños, producto de la tradición del abandono institucionalizado, sino de su patria, Portugal?

\section{La tradición del desamparo causado socialmente}

De una interesante obra sobre "El niño mexicano entre la caridad y el Estado" se puede tomar el siguiente pasaje:

Desde tiempos inmemoriales se lamenta la penosa situación de personas que no tienen donde vivir, hombres, mujeres y niños, duermen en las plazas y calles, en las entradas de las iglesias o de las casas de los patrones, en bancas del parque, en puestos vacíos del mercado o en las esquinas de cualquier edificio. No se sabe (...), si durante la colonia alguna vez se construyó algún refugio para estas personas desamparadas". 34

Esla descripción se refiere a la ciudad de méxico, en donde hay gente desamparada que vive y duerme en las calles, lo cual también puede comprobarse en otras ciudades latinoamericanas, como por ejemplo en los casos de Bogotá, Sao Paulo y Lima. Se comprobó que ya desde sus inicios eslas ciudades estaban afectadas por una gran población callejera. Esta estaba compuesta principalmente de indios, africanos e individuos de razas meztizas. Al plantearse la interrogante sobre las razones de la vida callejera de estas personas, suele hacerse referencia al rápido cambio social originado a raíz de la colonización española y portugesa, cuyo efecto en la raza indígena y africana fue un "shock" cultura|35, pues fueron dominados por los "conquistadores" blancos. Esta siluación se vuelve más clara a través de los que posiblemente fueron los primeros callejeros del "Nuevo Mundo", que según un decreto del Rey Carlos V en el año 1535, deben haber sido mestizos. Pues éste ordenaba "recoger a todos los niños regados", que eran producto de uniones de los conquistadores que llegaban con las mujeres indígenas. 36

Debe presumirse que las causas de la población callejera a la que aquí se refiere, son eminentemente latinoamericanas, que surgieron de un proceso histórico fomentado por la propia dinámica de los cambios sociales que se dan en las ciudades latinoamericanas.

¿Y qué ocurrió con estas personas desamparadas y sin techo que vivían y dormían en las plazas y calles? En Lima se combatió aún antes de que se propagara un desamparo igual, por medio del trabajo de clérigos quienes no sólo cuidaron sino también educaron a los indios dispersos y a los negros discriminados. En la cultura urbana colonial de Lima no se pudo "eslablecer" la existencia 
de ningún grupo de gente "desamparada" permanentemente.

La situación de Bogolá y Sao Paulo era completamente diferente, pues en estas ciudades se desarrolló una amplia población callejera desamparada. Estos últimos deben considerarse como discriminados, a quienes se les trataba con caridad, es decir que se les mantenía con vida por medio de limosnas. La misma sociedad que provocaba la discriminación y el desamparo de las personas, las tolera precisamente en su estado de discriminados y desamparados. Son perpetuados en esta condición, y se puede decir también que así son integrados al sistema social.

Esle fenómeno no puede comprenderse sin estudiar la relación que existe entre el mandamiento cristiano del amor al prójimo y de la población de mendigos que se desarrolló en Europa en la Edad Media. Ya el Papa Gregorio I (540604) daba estas enseñanzas: "Los pobres forman un estado que es necesario para los cristianos; por eso no debemos despreciarlos sino venerarlos como patronos. Al cristianismo le faltaría algo si ellos no existieran". 37 En el centro de ésta posición no se encontraba realmente el bienestar de los pobres, sino la tranquilidad de la propia conciencia, que se ganaba dando limosnas, lo cual no se podría haber hecho sin la existencia de los pobres. De esta forma se cré un expreso interés en conservar a los pobres como tales.

Las limosnas se daban indistintamente, lo cual a su vez dio lugar a un fuerte crecimiento de la población de mendigos. Esta se convirtió en una verdadera plaga. Surgieron escuelas de mendicidad, donde se enseñaban táclicas eficientes para provocar lástima a los cristianos. En el siglo XVI, la mendicidad se convirtio casi en un arte, en e! cual los niños jugaban un destacado papel. Algunos eran "alquilados" como mendigos profesionales, otros eran mutilados para hacerse acreedores de mayores limosnas. Los italianos eran especialmente ingeniosos en hacerse llagas y heridas falsas y en hacer aparecer como por arte de magia jorobas, etc. Muchos holgazanes que tenían capacidad de trabajar se mezclaban con los mendigos y les quitaban la ayuda a las personas que en verdad la necesitaban. El número de mendigos aumentó tanto, que aún con los recursos abundantes de la Iglesia éstos ya no fueron suficientes. Entonces en París cada noche se daba un milagro: los ciegos velan, los sordos oían y los inválidos caminaban.

Pronto se elevaron las críticas en contra de esas anomalías. La ayuda de la Iglesia a los pobres fue calificada como beneficencia malentendida, se condenó la entrega indiscriminada de limosnas, porque ésto había hecho que los hombres perdieran el hábito del trabajo, los había hecho holgazanes y dependientes. El sentimiento de la responsabilidad propia había sido sofocado en grandes círculos de la población. Muchos mendigos se habían convertido en vagabundos que representaban un peligro para la seguridad y el orden público. Se le achacó a la 
Iglesia el haber creado y luego mantenido a los pobres y pseudo-pobres que mendigaban. Martín Lutero, al igual que otros críticos contemporáneos, fomentó una atención regulada de los pobres, en la cual se seleccionaban los verdaderamente pobres, quienes después de una prueba profunda eran apoyados en una forma adecuada.38

También en la Iglesia Católica se comenzó a crilicar la limosna indiscriminada. Sin embargo, su posición siguió siendo ambivalente, pues no se condenó por completo la mendicidad, sino más bien se hizo una distinción entre medigos "malos y falsos". Eslos últimos, a diferencia de los primeros no merecían limosnas. La mendicidad fue reprimida y la lucha contra ella se fue concrelizando cada vez más. Sin embargo, el público general estaba acostumbrado a la presencia de los mendigos y a sus actos, por mucho tiempo los siguió protegiendo de los abusos de los agentes del orden -incluso se hablaba de la "complicidad" o hasta la "ilegalidad" de la población, que se mantuvo hasta los siglos XVIII y XIX. Gradualmente se fue imponiendo una ruptura con la mendicidad como institución ${ }^{39}$. Esta lenta ruptura fue comprensible hasla que se implementó poco a poco una asistencia estatal para los pobres, en forma de un "minimun vital". Mientras ésto no se logró, siguieron dependiendo de la tradición secular de la mendicidad — para no morir de hambre. 40

¿Qué relación existe entre esta tradición proveniente de Europa de la mendicidad "institucionalizada" y la población callejera latinoamericana, que se caracterizó primeramente por ser de razas mixtas, expulsada y desamparada? Como ya se ha expresado antes, también esta población callejera fue concebida por los clérigos y por la población como una obligación religiosa. Pero en Bogotá y Sao Paulo casi nadie se ocupó de estos discriminados y desamparados, sino que se quedó todo en dar limosnas en la calle. Pronto se propagó la mendicidad profesional proveniente de Europa, cuyos representantes, sin embargo, no deben confundirse con los que aquí se han llamado población callejera desamparada. También en el caso de las ciudades latinoamericanas mencionadas lo que hicieron lo mendigos profesionales fue aumentar la desgracia de los verdaderamente pobres - o sea de los que aquí se llaman discriminados y desamparados. En todo caso, también en Bogotá y Sao Paulo no se tardó en considerar a la población mendiga como una plaga. En Bogotá, algunas fuerzas progresistas con ideas enciclopedistas de Europa emprendieron algunos intentos de darle fin a los "conceptos arcaicos de la caridad indiscriminada" y combatir así la vagancia de muchos mendigos falsos o "parásitos". Se les quiso rehabilitar incorporándolos al "trabajo productivo".41 Sin embargo, estos esfuerzos fueron internumpidos después de corto tiempo por los disturbios independencistas y de las guerras civiles, los cuales contribuyeron, por su parte, a que nuevamente creciera la población callejera discriminada y desamparada.

En general puede partirse de que especialmente en el siglo XIX, los discrimi- 
nados y desamparados aumentaron en las calles de Bogotá y Sao Paulo, no sólo por situaciones tales como la liberación de indios y esclavos. También establecieron formas de vida especiales, "arreglándoselas" con la sociedad como discriminados y desamparados. Por ejemplo en Sao Paulo, a finales del siglo XIX, los ex-esclavos que venían en grandes grupos a la ciudad, comenzaron a recolectar la basura, lo cual era considerado por los blancos como una actividad indigna. Pero no sólo estos recolectores de basura podían estar seguros de recibir el desprecio de la sociedad establecida, no, lo mismo podían esperar otros grupos como las ex-sirvientas, como se desprende de la siguiente cita: "Cuando las acontecidas sirvientas quedan inútiles para el servicio, vagan por las calles y plazas entregadas a todos los vicios imaginables, sin que ellas mismas tengan conciencia exacta de lo que hicieron ni de lo que hacen".42

A lo que hace referencia el autor de estas líneas con relación a la capital colombiana a finales del siglo pasado es al fenómeno de las bellas sirvientas que eran obligadas a prestar servicios amorosos a sus patrones - no importando si a padres o hijos. Cuando quedaban en estado de embarazo, éste las inhabilitaba para el servicio de la casa y se encontraban nuevamente expulsadas y desamparadas en las calles, donde contribuían a un aumento de la población callejera y no era raro que, debido a la necesidad, cayeran o fueran inducidas a la prostitución. Como ya se mencionó, son procesos sociohistóricos especiales latinoamericanos como el colonialismo, la esclavilud, la explotación sistemática, la discriminación racial, etc., los que provocaron la reacción de discriminación y que llevaron al fenómeno de la población callejera, cuyo desamparo - que no podía ser mejor expresado que con el caso de las sirvientas de la cita anterior- se pudo expandir e "institucionalizar" sobre la base de una tradición importada de Europa de dar limosna.

Se debe suponer que las condiciones de vida más precarias eran la vida diaria de la población callejera desamparada, que no podía satisfacer las necesidades físicas y psíquicas más elementales, que el desamparo se convirtió en un "estilo de vida" con el que ya nacían los niños. La apatía, la desnutrición, los trastomos psíquicos como miedos, depresiones, ansiedades, etc., pertenecen a la rulina de los desamparados, quienes sobreviven y se reproducen a través de las limosnas. 43 Por un lado como despreciados y por el otro como dignos de lástima, se han convertido en un componente tradicional de sociedades que obviamente hasta la fecha no han asumido sus verdaderos problemas - los cuales han pasado de atendidos y se han reproducido por siglos- y que en vez de eso, los alimentan siempre con limosnas. De esta manera se contribuía y se contribuye al mantenimiento de un "estilo de vida de desamparo" — se refiere a la tradición del desamparo causado socialmente.

Se puede trazar una línea direcla de unión entre el desamparo de la población callejera de Bogotá y Sao Paulo de antaño y las familias de los niños callejeros 
que en un análisis 44 fueron catalogados como desamparados. Ya en este análisis se puso de manifiesto que el desamparo de los niños callejeros equivale casi siempre al desamparo de sus familias, que ellos han recibido en parte como herencia - por ejemplo en forma de deficiencia o perturbación mental- en parte como educación. Además se demostró que no era extraño que los niños callejeros desamparados de Bogotá y Sao Paulo hayan vivido o vivieran con sus familias por cierto tiempo- a diferencia de otros niños de la calle - lo cual señala la existencia tradicional de una población callejera. En algunos casos, se pudo encontrar incluso niños que prácticamente nacieron en la calle y la consideran como su hogar "natural". Tanto en Bogotá como en Sao Paulo, el "oficio" tradicional en estos círculos parece ser -el de carretonero, que recolecta cartones y otros desechos- independientemente de pedir. En las ciudades descritas se ve de día y de noche grupos de personas trabajando, a veces en familia, con los carretones, lo cual es despreciado y considerado por la población como una forma de mendigar. 45

Entre los niños callejeros desamparados se observa que sus débiles madres -on quienes mantenían un fuerte lazo afectivo- no pueden desempeñar su papel de educadoras, lo cual muchas veces trae como consecuencia que todos sus hijos quedan bajo la responsabilidad de la asistencia social. Por otro lado se mostró que con frecuencia las madres, muchas veces apáticas - descritas por los educadores callejeros como falalistas, derrotadas, desmotivadas y pasivas- no sabían que hacer con sus hijas hembras, más que colocarlas a muy temprana edad como "sirvientas" en alguna familia, de la misma forma como ellas mismas lo habían sido.

Aquí surge una interrogante similar a la que se planteó en la tradición del abandono institucionalizado: ¿en qué medida los intereses sociales juegan aquí el papel de mantener la tradición del desamparo causado socialmente?

En este punlo se toca el problema del que se suele hablar en Latinoamérica de la ignorancia popular, que se ha ido reproduciendo por un sistema de educación desigual, en el cual los mecanismos de selección que se han establecido no le permiten a una gran parte de la población gozar en suficiente medida de la educación. Sobre todo en el Brasil, el nivel de "ignorancia" reproducida sistemáticamente es muy elevado. A finales del tiempo de la Colonia, la población que no era libre estaba compuesta casi exclusivamente por analfabetos. Todavía en los años sesenta del siglo XX habían quejas de un alto porcentaje de "drop-outs" y reprobados. 46 Esta problemática todavía se ha mantenido en forma masiva no sólo en el Brasil, sino también en muchos países latinoamericanos, lo cual tiene una relación direcla con el sistema educativo existente. No puede pasar desapercibido un cierlo desinterés por parte de las clases dominantes en Latinoamérica por abolir la ignorancia de considerables partes de la población. 47 
Se debe asumir que entre los niños callejeros que antes existieron en Bogotá y Sao Paulo, los "chinos de la calle" y los "moleques de rua" 48 , se encontraban muchos hijos de individuos o familias desamparadas. Se debe suponer que estos niños callejeros desamparados y de color forman el segundo gran grupo original de niños callejeros latinoamericanos, o sea que a la par de los niños expósitos, en su mayoría blancos, estos niños desamparados de color representan la mayoría de los primeros niños callejeros latinoamericanos existentes aún en el tiempo de la Colonia. Dicho con otras palabras: La razón específicamente latinoamericana de la existencia de la infancia callejera debe verse por un lado en la tradición del abandono instilucionalizado de niños, y por otra, en la tradición del desamparo causado socialmente - tradiciones que todavía subsisten en muchas partes de latinoamérica.

\section{Notas}

1. Una discusión más amplia de este tema se encuentra en el séptimo capítulo de mi estudio "Los niños de la calle en América Latina. Estudio comparativo en Ciencias Sociales: Bogotá (Colombia), Sao Paulo (Brasil) y Lima (Peri)", publicado en alemán en 1993. Ver Roggenbuck, 1993, 225 pp.

2. Por "niño (s) de la calle", "Niño (s) callejero (s)" se entiende la población de ambos scxos de la edad de hasta 17 años que viven y duermen varios días conseculivos en la calle sin ser acompañados por adultos.

3. Aquí debe remontarse sobre lodo a la Antigua Roma, donde el abandono de niños estaba bastante arraigado; ver Pciper, 1966: 197 pp.

4. Conrad, 1909: 315 pp.; Mc Laughin, 1980: 177 pp.

5. Las siguientes exposiciones relativas a la diferencia del abandono "romano" y las instituciones "germanas" de protección al menor tienen carácter típico-ideal. De modo que no debe tomarse en consideración el hecho de que Suecia y Dinamarca, contrariamente a la regla, hayan seguido el abandono romano. Ver Peiper, 1966: 197 pp., quien hace referencia a este hecho, pero sin profundizar en él.

6. Fold, 1927: $175 \mathrm{pp}$.

7. Feld, 1914: $12 \mathrm{pp}$.

8. Pciper, 1966: $197 \mathrm{pp}$.

9. Cita tomada de Pciper, 1966: 200 pp.

10. Feld, 1914: $10 \mathrm{pp}$.

11. Cita tomada de Peiper, 1966: 200 pp.

12. Peiper, 1966: $195 \mathrm{pp}$.

13. Peiper, 1966: 206 pp.; Conrad, 1909: 318 pp.

14. En la antigua Roma se acostumbraba vender como esclavos a los expósilos después de haberlos criado. A los varones los entrenaban también para gladiadores, las hembras cran inducidas a la prostitución. Peiper, 1966: $176 \mathrm{pp}$.

15. Pina, 1964: 360 pp. Gonzalbo Aizpuru, 1982: 413,423 pp.; Pciper, 1966: 231 pp.

16. Feld, 1927: $179 \mathrm{pp}$.

17. Ver Roggenbuck, 1993: 72 pp., 113 pp. y 152 pp.

18. Para el caso, la ciudad de méxico, Bogotá, Salvador y Río de Janciro tenían ya en el siglo XVIII tornos oficiales de expósitos, aún antes que paris los tuviera; Velasco Ccballos, 1935: 67 pp.; Iriartc, 1988: 220 pp.; Azzi, 1987: 14 pp. 
19. Silva, 1980: 95 pp.

20. Soares, 1959: 34 pp.

21. Conrad, 1909: 318 pp.

22. Felsman, 1984: 14 pp.

23. Se calculaba que la cantidad de niños callejeros en Rusia en 1922 era de 7a 9 millones; Anweiler, 1984: 13 pp. En relación a la protección de los expósitos en Rusia - por cierto en Moscú existía la casa de expósilos más grande del mundo - ver Conrad, 1909: 317 pp. y Peiper, 1966: 210,224,227 pp.

24. Conrad, 1909: 315 pp.; Pciper, 1966: 198 pp.

25. Donde está mejor documentada su aclividad es en la casa de expósitos de Rfo de Janeiro donde empezaron en 1857. Soares, 1959: 136 pp. También en las casas de expósitos de Bogolá y Lima se ha comprobado su influencia. Córdovez Moure, 1962: 914 pp.; Middendorf, 1893: 509 pp.

26. En Sao Paulo funcionó hasta 1950 una rueda de expósitos; en la Habana hasta la Revolución a finales de los años cincuenta. Peiper, 1966: 241 pp. Cabe mencionar que en algunas provincias latinoamericanas "atrasadas" deben haber existido esos tornos de expósitos aún en los años $\mathbf{8 0}$.

27. Gaede/Burkard, 1985: 34 pp.

28. Pereira/Görgen, 1982: 162 pp.

29. Marques, 1976: $80 \mathrm{pp}$.

30. Esto se desprende de la literatura especializada brasileña sobre los "menores instilucionalizados". También en relación a los niños que se abandonaban antes legalmente en Europa, la literatura especializada destaca el cargo de conciencia, el arrepentimiento de las madres de entonces. Peiper, 1966: 207 pp.

31. Nogueira Filho, 1956: $116 \mathrm{pp}$.

32. Junqueira, 1986: $29 \mathrm{pp}$.

33. Edmundo, 1987: 29 pp.

34. Velasco Ceballos, 1935: 29 pp.

35. Stubbe, 1988: 3 pp.

36. Velasco Ceballos, 1935: 21 pp.

37. Cita lomada de Peiper, 1966: 394 pp.

38. Pciper, 1966: 394 pp.

39. Sloffels, $1977: 33,44,90 \mathrm{pp}$.

40. Peiper, 1966: 399 pp.

41. Iriarte, 1988: 223 pp.

42. Córdovez Moure, 1962: 928 pp.

43. Comparar con ésto la exposiciones del "sislema de impaclo" de la infancia callejera (brasileña) en Stubbe, 1988: 5 pp. También "Cultura de la pobreza" de Oscar Lewis en Goctze, 1976: 144 pp. y Goctzc, 1983: 206 pp.

44. Ver Roggenbuck, 1993; 198 pp.

45. Las apreciaciones que se hacen aquí sobre los carretoneros de Bogotá y Sao Paulo son de carácter lípico idcal. No necesariamente en lodos los casos los carreloneros lienen que ser desamparados. Durante la investigación de campo que ha servido de base para el cstudio de Roggenbuck (1993), pudieron encontrarse con frecuencia lambién carretoncros que no eran desamparados, pero que no obstante tenian que luchar con ese estigma social.

46. Heimer, 1977: 37 pp. 
47. Ver al respecto las exposiciones relativas al sistema escolar peruano y latinoamericano en Castillo Rios (sin año): 49 pp. y en Rodríguez F., 1988: 24,46,50 pp.

48. Estas designaciones hacen una clara referencia, en sentido etimologico, a su origen indígena o africano, lo cual al principio se consideró como una característica esencial de los niños callejeros desamparados.

\section{Bibliografía}

Anweiler, Oskar (1984): “Leben, Werk und Bedeutung A.S. Makarenkos", en: Makarenko, Anton S.: Ein pädagogisches Poem. Frankfurt am Main, Berlin, Wien: Ullstein, Pág. 5-29.

Azzi, Riolando (1987): "A igreja e o menor abandonado", en: Vida pastoral, año XXVIII, No. 132, Sao Paulo, Pág. 14-18.

Castillo Rios, Carlos (sin año): Los niños del Perí. Lima: Editora Lima (4a. Edición).

Conrad, J. (1909): "Findelhäuser oder Findelanstalten", in: Conrad, J. Elster, L.; Lexis W.; Loening, E. (Edts.): Handwörterbuch der Staatswissenschaften, Band 4. Jena: Gustav Fischer (3a Edición), Pág. 315-322.

Cordovez Moure, José Maria (1962): Reminiscencias de Santafé y Bogotá. Madrid: Aguilar (2a Edición).

Edmundo, Lygia Pereira (1987): Instituiçao: escola da marginalidade? Sao Paulo: Cortez.

Feld, Wilhelm (1914): "Findelhäuser in Deutschland?", en: Zeitschrift für das Armenwessen, XV. Jahrgang, Heft 1, Berlin, Pág. 1-16.

Feld, Wilhelm (1927): "Findelfürsorge", en: Elster, Ludwig; Weber, Adolf; Wieser, Friedrich (Edts.) : Handwörterbuch der Staalswissenschaften. Jena: Gustav Fischer (4a Edición), Pág. 174- 186.

Felsman, J. Kirk (1984): "Abandoned children: a reconsideration", en: Children Today, Vol. 13 (3), May-June 1984, Washington D.C., Pág. 13-18.

Figueredo, Paulo Nunes Augusto de (1984): “O parlamento brasileiro e o problema do menor abandonado", en: Revista de Información Legislativa. Ano 21, No. 82, Brasilia, Pág. 93-130.

Gaede, Peter-Matthias; Burkard, Hans Jürgen (1985): "Die Straßenkinder von Sao Paulo", in: GEO, No. 6, Juni 1985, Hamburg, Pág. 12-40.

Goetze, Dieter (1976): Entwicklungssoziologie. München: Wilhelm Goldmann

Goetze, Dieter (1983): Entwicklungspolitik 1. Soziokulturelle Grundfragen. Paderborn; München; Wien; Zürich: Ferdinand Schöningh.

Gonzalbo Aizpuru, María Pilar (1982): "La casa de los niños expósitos de la ciudad de México", en: Historia mexicana. Vol. 31 (32), No.3=123, México, Pág. $409-430$.

Heimer, Franz-Wilhelm (1977): "Erziehung, Gesellschafisstruktur und Politik in Brasilien", en: Zeilschrift Fur Padagogik, 23. Jahrgang, Weinheim, Pág. 35-55.

Iriarte, Alfredo (1988): Historia de Bogotá (Tomo I). Bogotá: Villegas.

Junqueira, Lia (1986): Abandonados. Sao Paulo: Icone.

Marques, Joao Benedito de Azevedo (1976): Marginalizaçao: menor e criminalidade. Sao Paulo: Mc Graw-Hill do Brasil.

Mclaughlin, Mary Martin (1980): "Überlebende und Stellvertreter: Kinder und Eltern zwischen dem neunten und dreizehnlen Jahrhundert", en: de Mause, Lloyd (Ed.): Hört ihr die Kinder weinen. Frankfun am Main: Suhrkanp, Pág., 147-262.

Middendorf, Ernst Wilhelm (1893): Perú. (Tomo l: Lima). Berlin: Robert Oppenheimer. 
Nogueira Filho, Paulo (1956): Sangue, Comupsao e vergonha S.A.M. Sao Paulo: Libertas Peiper, Albrecht (1966): Chronik der Kinderheilkunde. Leipzig: Georg Thieme (4a Edición).

Pereira Jr., Jesse Torres; Goergen, Hermann M. (1982): "15 bis 20 Millionen "verlassene Jugendliche"?", en: Dutsch-brasilianische hefte, 3/82, Nümberg (21), Pág. 156-173.

Pina, Luis de (1964): "Da roda dos expostos á "carta dos direitos" de crianca", en: Boletin Culinral, Vol. 27, fases 3/4, Porto, Pág. 327-373

Rodríguez F., Jaime (1986): "El muchacho de la calle. ¿Educación vs. marginalidad o marginalidad vs. educación?", en: Educación hoy. Año XVI, No. 94, Bogota, Pág. 21-44.

Roggenburck, Stefan (1993): Straßenkinder in Lateinamerika. Sozialwissenschaftliche Vergleichsstudie: Bogotá (Kolumbien), Sao Paulo (Brasilien) und Lima (Perú). Frankfurt am Main, Berlin, Bern, New York, Paris, Wien: Peter Lang.

Silva, María Beatríz Nizza da (1980): "O problema dos expostos na capitania de Sao Paulo", en: Revista de Historia económica e social, No. 5, Lisboa, Pág. 95-104.

Soares, Ubaldo (1959): $O$ pasado heroico da case dos exposlos. Rlo de Janeiro

Sloffels, Marie-Ghislaine (1977): Os mendigos na cidade de Sao Paulo. Rio de Janeiro: Paz e Terra.

Stubre, Hannes (1988): Moleques. Mannheim. (Texto inedilo).

Velasco Ceballos, Romulo (1935): El niño mexicano ante la caridad y el estado. México: Beneficencia pública en el D.F. 